\title{
The Function of Personality in Suicidal Ideation from the Perspective of the Interpersonal-Psychological Theory of Suicide
}

\author{
Marc Baertschi ${ }^{1,2, *(\mathbb{D})}$, Alessandra Costanza ${ }^{3}$, Alessandra Canuto ${ }^{4}$ and Kerstin Weber ${ }^{5}$ \\ 1 Service of General Psychiatry and Psychotherapy, Nant Foundation, Avenue des Alpes 66, \\ 1820 Montreux, Switzerland \\ 2 Faculty of Psychology, University of Geneva, Boulevard du Pont d'Arve 40, 1205 Geneva, Switzerland \\ 3 Psychiatry Department, SS. Antonio e Biagio e Cesare Arrigo Hospital, Via Venezia 16, \\ 15521 Alessandria, Italy; alessandra.costanza@ospedale.al.it \\ 4 Executive and General Management Service, Nant Foundation, 1804 Corsier-sur-Vevey, Switzerland; \\ alessandra.canuto@nant.ch \\ 5 Division of Institutional Measures, Medical Direction, Geneva University Hospitals, \\ Les Voirons-Chemin du Petit-Bel-Air 2, 1225 Chêne-Bourg, Switzerland; kerstin.weber@hcuge.ch \\ * Correspondence: marc.baertschi@nant.ch; Tel.: +41-21-965-7600
}

Received: 15 February 2018; Accepted: 29 March 2018; Published: 30 March 2018

\begin{abstract}
The Interpersonal-Psychological Theory of Suicide (IPTS) has been increasingly studied over the last years, responding to the demand for a valid framework addressing suicidality. Yet, only a few studies have explored the function of personality in the IPTS and none with clinical patients. We aimed to contribute to fill this gap in investigating the relationship between personality as conceptualized by the Five-Factor Model, the IPTS constructs, and a dimensional measure of current suicidal ideation. We conducted correlation, multiple linear regression, and path analyses based on a trait-interpersonal framework in a sample of 201 individuals visiting the psychiatric emergency room of a general hospital with current suicidal ideation. Neuroticism (positively) and openness (negatively) predicted perceived burdensomeness, while neuroticism (positively) and extraversion (negatively) predicted thwarted belongingness. Higher conscientiousness and lower extraversion were both predictors of the acquired capability for suicide. However, none of the models involving path analyses with IPTS variables as mediators of the relationship between personality traits and suicidal ideation was adequately adjusted to the data. Thus, it appears that personality plays a significant albeit modest role in suicidality when considered from an IPTS perspective. As personality is frequently assessed in the clinical routine, health professionals should consider it as complementary to detect individuals at risk of or presenting suicidal ideation.
\end{abstract}

Keywords: personality; Five-Factor Model; Interpersonal-Psychological Theory of Suicide; suicidal ideation

\section{Introduction}

The clinical management of patients who attempted suicide or have suicidal ideation suffers from the scarcity of comprehensive models accounting for the suicide phenomenon [1]. The Interpersonal-Psychological Theory of Suicide (IPTS) was designed in this regard as a framework proposing that the most dangerous kind of desire for suicide stems from two constructs, namely feelings of not belonging to one's social group (thwarted belongingness) and the perception of being a burden for significant others (perceived burdensomeness). Additionally, the theory specifies that acting on this desire for suicide is only possible if one has acquired the capacity to do so, assessed by a third construct labeled the acquired capability for suicide [1,2]. 
Tested in an increasing number of studies during the past decade, the predictions of the IPTS have not been unanimously supported [3]. In this context, further research on possible determinants of thwarted belongingness (TB), perceived burdensomeness (PB) and the acquired capability for suicide (AC) is warranted. Specifically, it has been pointed out that the IPTS does not account for the propensity to engage in suicide behavior. This, in other words, refers to possible pre-existing vulnerabilities for suicide, which could notably be appraised in terms of personality [4]. To our knowledge, the founding texts of the IPTS did not mention personality, although its role has been considered in recent IPTS studies from both categorical [5,6] and dimensional perspectives [7-14].

A trait model of personality, the Five-Factor Model (FFM) [15] has been adopted as consensual framework to determine each person's individuality as a function of five broad dimensions: neuroticism $(\mathrm{N})$, extraversion $(\mathrm{E})$, openness $(\mathrm{O})$, agreeableness $(\mathrm{A})$ and conscientiousness $(\mathrm{C})$. These dimensions have been progressively identified in the second half of the twentieth century starting with the pioneering work of Eysenck [16] who initially identified the "Big Two" N-E pair. Neuroticism refers to a temperamental measure of emotional health comprising components such as fear, anger and impulsivity. Extraversion relates to variables like warmth, assertiveness and activity, and has been viewed as a predisposition toward positive effects. Taken together, $\mathrm{N}$ and $\mathrm{E}$ constitute independent, nonetheless interrelated, sources of subjective well-being [17]. The "high $\mathrm{N} /$ low E" pattern is notably predictive of depressive symptoms and hopelessness [18] as well as suicidal ideation [19]. Agreeableness describes traits usually displayed in interpersonal relationships, such as courtesy, altruism, and compliance. Openness has often been associated with intellect and depicts a tendency toward a variety of experiences, ranging from inner thoughts or fantasy to actions and ideas (hence frequently referred to as "openness to experience"). Finally, conscientiousness concerns variables such as self-discipline, deliberation and dutifulness, and has been associated with educational achievement and volitional aspects.

Despite the absence of theoretical assumptions, the existing literature allows us to make inferences on the way personality traits could account for variability in IPTS constructs. Derived from the FFM, the Five-Factor Theory of personality [20] postulates that traits "influence patterns of thoughts, feelings, and actions" (p. 165). It could therefore be hypothesized that an individual's expression of PB, TB and AC may partly stem from the specificity of his/her personality traits.

First, $\mathrm{PB}$ and $\mathrm{TB}$ have a strong cognitive component as they develop from non-necessarily objective perceptions of lack of connectedness or social isolation [2,21]. High levels of $N$ have been associated with distorted cognition [22] and high levels of $\mathrm{E}$ with perceived social support, notably belongingness [23]. Additionally, high levels of A have been related to the ability of maintaining positive interpersonal relationships and to interpersonal adjustment [24]. A tentative hypothesis would thus be that a conjoint presence of high N, low E and low A creates favorable dispositions for PB and TB.

The only five studies quantitatively addressing the relationships between the FFM and the IPTS $[4,9,11,13,14]$ support this assumption. Indeed, $\mathrm{N}$ was positively associated with $\mathrm{PB}$, and $\mathrm{E}$ negatively associated with both $\mathrm{PB}$ and $\mathrm{TB}[9,13]$. $\mathrm{N}$ was also positively and E negatively associated with suicide proneness [11,14], a construct including "engagement in overtly suicidal behavior as well as in risk-taking and potentially injury-producing behaviors, coupled with a lack of health and safety behaviors, and/or a lack of self-worth and self-enhancing behaviors" ([25], p. 416). Additionally, Cramer and colleagues $[11,13,14]$ tested the mediating effects of IPTS variables on the relationship between the FFM and suicide proneness using structural equation modelling (SEM). Consistently over three different populations of pre-incarcerated offenders, members of the lesbian, gay and bisexual community, and university students, they found that, respectively, PB positively mediates the influence of $\mathrm{N}$ and TB negatively mediates the influence of $\mathrm{E}$ on suicide proneness. Moreover, the two studies including $\mathrm{O}, \mathrm{A}$ and $\mathrm{C}$ in the SEM analyses [11,14] showed that TB negatively mediates the influence of $\mathrm{A}$ on suicide proneness, and that neither PB nor TB have a mediating effect on the pathway between $\mathrm{O}$ and suicide proneness. Other effects were also identified but inconsistently, which led the authors to suggest that trait-interpersonal pathways articulate differently in various 
population groups [11]. The same hypothesis was raised by Ireland and York [4], whose sample was comprised of women prisoners, to explain the unexpected association between increased extraversion and self-injurious behavior.

Second, the IPTS proposes that AC is progressively acquired through pain and fear exposure via mechanisms of habituation and opponent processes [2]. The question arises as to whether certain patterns of personality traits could favor the activation of these mechanisms. Habituation has been traditionally defined as a "decrement in magnitude of unlearned responses $(\ldots)$ due to repetitive stimulatory activation" ([26], p. 385). It has been experimentally assessed through a variety of physiological measures such as the acoustic startle response and skin conductance recording. To our knowledge, the relationship between habituation and personality has never been specifically studied within the context of AC; however, should a certain pattern of personality traits foster habituation in general, this could also apply to fear and pain habituation in particular, the latter two dimension being germane to AC. We only found one study addressing the relationship between personality, pain and habituation [27], and this study showed that individuals with low $\mathrm{N}$ habituate faster to pain than those with high $\mathrm{N}$ levels. However, in another study using the FFM, individuals with a personality profile of high N/low E-O-A-C displayed smaller amplitude of the P300 component of the auditory event-related cortical potential, which suggests faster habituation [28]. Although less directly relevant to AC, habituation and personality in general have not yielded constant associations, as illustrated by studies using an acoustic startle response paradigm. Faster habituation was associated with high-N individuals by Blanch and collaborators [29] but with high-E participants by LaRowe and colleagues [30], while Akdag et al. [31] did not find any relation with personality traits at all. Differences in theoretical approaches and measurement methods have probably fostered such inconsistency. In comparison with $\mathrm{N}$ and $\mathrm{E}$, the other three FFM dimensions have been far less subject of investigations.

For these reasons, research on personality and the IPTS mainly remains exploratory at the current stage. This study was therefore designed to add a further contribution to the existing literature in; first, investigating the predictive character of FFM personality traits on the three main constructs of the IPTS and a measure of suicidal ideation, and; second, assessing the effects of IPTS variables as mediators of the relationship between personality traits and suicidal ideation. Based on the existing data, we expected that $\mathrm{N}$ would positively predict $\mathrm{PB}$ and $\mathrm{E}$ negatively predict $\mathrm{PB}$ and $\mathrm{TB}$. We also hypothesized that $\mathrm{PB}$ would mediate the positive influence of $\mathrm{N}$, and $\mathrm{TB}$ the negative influence of both $\mathrm{E}$ and $\mathrm{A}$, on suicidal ideation. This boils down to replicate the hypothesized trait-interpersonal pathways progressively elaborated by Cramer and collaborators [11,13,14]. Additionally, we decided to investigate the possible mediating function of $\mathrm{AC}$ in the relationship between FFM traits and suicidal ideation. Although the IPTS posits that AC is independent from suicide desire [2], a relationship between these two constructs was found in about $57 \%$ of reviewed studies [3]. Because of the absence of consistent findings in the habituation literature, we included the five FFM personality traits as predictors in our analyses.

\section{Materials and Methods}

\subsection{Participants and Procedure}

The study procedure was made of self- and clinician-administered questionnaires including a range of sociodemographic inquiries. A total of 368 individuals visiting the psychiatric room of the emergency department at the Geneva University Hospitals, Switzerland, for a suicide attempt or suicidal ideation were offered to participate to the study. Among them, 129 refused for various reasons such as difficulty concentrating, lack of interest, and problems understanding French. Additionally, 38 were excluded by the psychiatrist in charge of study inclusion due to serious suspicion regarding data quality after noticing obvious lack of motivation-illustrated by repeated patterns of answers or systematic refusal to fill in questionnaires-or procedural problems (e.g., absence of signed consent form). Thus, the final sample was comprised of 201 participants, aged $33.4 \pm 14.5$ years old, predominately composed of women $(60.7 \%)$, Swiss citizens $(57.7 \%)$, currently not in a relationship 
$(65.7 \%)$, without children $(60.2 \%)$, and either working or studying (57.7\%). Most participants had a history of suicide attempts $(63.2 \%)$ and a current psychiatric diagnosis $(88.6 \%)$ according to the Mini-International Neuropsychiatric Interview [32] with the most prevalent diagnosis being an episode of major depression $(69.7 \%)$, followed by alcohol dependence $(16.9 \%)$ and non-alcohol substance dependence $(10 \%)$. Additional sociodemographic information on the sample and recruitment procedure has been published elsewhere [33]. The study procedure and contents were approved by the local Research Ethics Committee and all participants signed an informed consent before study entry.

\subsection{Measures}

The personality profile was evaluated with the French version of the revised NEO-Five-Factor Inventory (NEO-FFI-R) [34,35], whose 60 items were selected from the longer NEO PI-R [36] in order to provide a score for the five personality dimensions of the FFM (i.e., N, E, O, A and C). Each item is calculated with a $0-4$ Likert score, leading to a maximum score of 48 per dimension. Internal consistencies were good for $\mathrm{C}(\alpha=0.849,95 \% \mathrm{CI}(0.816,0.878))$, acceptable for $\mathrm{N}(\alpha=0.758,95 \% \mathrm{CI}$ $(0.705,0.805))$ and $\mathrm{E}(\alpha=0.705,95 \% \mathrm{CI}(0.641,0.762))$, and questionable for $\mathrm{O}(\alpha=0.681,95 \% \mathrm{CI}(0.612$, $0.741))$ and $\mathrm{A}(\alpha=0.680,95 \% \mathrm{CI}(0.611,0.742))$.

The desire for suicide, as conceptualized by $\mathrm{PB}$ and $\mathrm{TB}$, was assessed with the revised version of the Interpersonal Needs Questionnaire (INQ-R) [37], which proposes a subscale to evaluate PB (6 items, score range: 6-42) and a subscale to evaluate TB (9 items, score range: 9-63). For both scales, higher scores indicate stronger feelings of the construct measured. Internal consistency was good for PB $(\alpha=0.866,95 \%$ CI $(0.835,0.893))$ and acceptable for TB $(\alpha=0.749,95 \%$ CI $(0.693,0.798))$.

The acquired capability for suicide was assessed with the German Capability for Suicide Questionnaire (GCSQ) [38], which proposes three subscales of fearlessness of death (5 items, score range: 5-25), pain tolerance (five items, score range: 5-25), and perceived capability for suicide (1 item, score range: $1-5)$. The summation of these subscores provides a total score for AC. In all subscales, higher scores indicate greater capability for suicide. The internal consistency of the GCSQ was good $(\alpha=0.880,95 \%$ CI $(0.854,0.903))$.

We finally assessed suicidal ideation with the Scale for Suicide Ideation (SSI) [39], a self-administered questionnaire comprised of 19 items rated on a 3-point Likert scale (score range: $0-38$ ). The SSI has been validated in French [40,41]. In our sample, internal consistency was good $(\alpha=0.844,95 \%$ CI $(0.811$, $0.874)$ ). In the absence of versions validated in French, the GCSQ and the INQ-R were translated and adapted according to the WHO guidelines [42] (http:/ /www.who.int/substance-abuse/research_ tools/translation/en/).

\subsection{Statistical Analyses}

A full set of descriptive statistical analyses including means, standard deviations, skewness, kurtosis, and bivariate Pearson's correlations were initially computed for all variables of interest. We then explored the predictive value of the FFM personality traits $(\mathrm{N}, \mathrm{E}, \mathrm{A}, \mathrm{O}$, and $\mathrm{C})$ in the variance of each IPTS variable $(\mathrm{PB}, \mathrm{TB}$, and $\mathrm{AC})$ as well as of a measure of current suicidal ideation (SI) with multiple linear regression models. Missing data appeared in three cases out of 201, which constitutes a ratio of 0.015 , and were handled with multiple imputation. In line with the recommendations of White, Royston and Wood [43], who suggested that the imputation number should be equal or superior to the percentage of cases containing missing values, we conducted statistical analyses after generating five datasets. We decided to rely on original data - which included missing data-to assess parameters that could not be computed through combined estimation from multiple imputations (e.g., standard deviations, Fisher's test in multiple regression models). These analyses were performed with SPSS version 24.0 (IBM SPSS, Chicago, IL, USA). Exploratory and control analyses (e.g., residuals, outliers, heteroscedasticity, multicolinearity) were conducted for every analysis. No assumption violation was observed.

In a second step, we investigated the mediating function of IPTS variables in the relationship between FFM personality traits and current SI using a path analysis framework. To this end, we 
specified six models. The first one drew on the literature and hypothesized that PB mediates a positive relationship between $\mathrm{N}$ and SI and a negative relationship between $\mathrm{E}$ and SI, whereas TB mediates negative relationships between $\mathrm{E}$ and SI and between $\mathrm{A}$ and SI. We then compared this model with a nested model adding direct pathways between FFM variables (i.e., N, E, and A) and SI. A similar procedure was replicated for the next two models. Both explored the mediating function of AC in the relationship between the FFM and SI, the second one including direct effects; yet, in light of the sparse, inconsistent findings addressing personality and AC (or rather AC's possible proxies) we decided to include the five FFM variables as predictors without further specifying research hypotheses.

Finally, we tested two additional models that included PB/TB, respectively AC, as mediating variables. These models were designed in including FFM, IPTS and SI variables showing significant relationships in regression analyses. We expected these models to demonstrate a better fit to the data than the above-mentioned models based on the literature; however, direct statistical comparisons were not possible as the last two models were not nested within the initial four.

Path analyses were conducted using Amos version 23.0 (IBM SPSS, Chicago, IL, USA), which estimates missing data with a full information maximum likelihood estimator. Amos nevertheless does not compute confidence intervals for parameters estimated from databases containing missing data, as well as standard errors and $p$-values for some analyses (e.g., indirect effects). We used Statistica version 12.7 (StatsSoft Inc., Tulsa, OK, USA) to estimate the $\chi^{2}$ difference between nested models (i.e., model 1 vs. model 2, and model 3 vs. model 4).

\section{Results}

\subsection{Descriptive Statistics}

Means, standard deviations, skewness, kurtosis, and bivariate Pearson's correlations for the variables of interest of this study are displayed in Table 1. Taking sample size into account, Z-test values for skewness (between $|0.052|$ and $|2.488|$ ) and kurtosis (between $|0.064|$ and $|2.825|$ ) suggest that normality was preserved in the sample distribution of each variable [44]. The four personality traits of $\mathrm{E}, \mathrm{O}, \mathrm{A}$, and $\mathrm{C}$ were all positively associated with one another, except for $\mathrm{O}$ and $\mathrm{C}$ whose correlation was not significant. On the other hand, $\mathrm{N}$ was negatively related to $\mathrm{E}$ and $\mathrm{C}$, and positively to O. The IPTS variables of $\mathrm{PB}$ and TB were positively related to each other and to SI. The variables associated with AC were SI, PB and C, all positively. Other IPTS-FFM significant relationships were $\mathrm{N}$ with $\mathrm{PB}$ and $\mathrm{TB}$ (both positively), $\mathrm{E}$ with $\mathrm{PB}$ and $\mathrm{TB}$ (both negatively), and A with TB (negatively). Finally, significant correlations between FFM traits and SI concerned N (positively), $\mathrm{E}$ and $\mathrm{A}$ (both negatively). Ranging from $|0.143|$ to $|0.453|$, significant correlations represented small to medium effect sizes $(r)$ according to the criteria of Cohen [45].

\subsection{Regression Analyses}

We first built three multiple linear regression equations including the five personality dimensions as predictors and, respectively, $\mathrm{PB}, \mathrm{TB}$, and $\mathrm{AC}$ as the dependent variable. The initial model accounted for a significant proportion of the variance in $\mathrm{PB}, F(5,193)=5.115$, Adjusted $R^{2}=0.094, p<0.001$. The criterion was predicted by increased levels of $\mathrm{N}(b=0.422, t=4.186, p<0.001)$ and decreased levels of $\mathrm{O}(b=-0.251, t=-2.248, p=0.025)$. However, no regression effect was found for $\mathrm{E}(b=-0.160$, $t=-1.391, p=0.164), \mathrm{A}(b=-0.024, t=-0.212, p=0.832)$, and $\mathrm{C}(b=0.048, t=0.563, p=0.573)$. The second model explained a significant proportion of the variance in $\mathrm{TB}, F(5,193)=7.175$, Adjusted $R^{2}=0.135, p<0.001$, with TB being predicted by N $(b=0.338, t=3.265, p=0.001)$ and $\mathrm{E}(b=-0.364$, $t=-3.092, p=0.002)$. While the predicting value of $\mathrm{O}(b=-0.223, t=-1.932, p=0.053)$ and A $(b=-0.213, t=-1.868, p=0.062)$ approached the significance threshold, $\mathrm{C}(b=0.084, t=0.954$, $p=0.340)$ was not related to the criterion. Finally, the set of FFM variables predicted variance in AC, $F(5,193)=3.203$, Adjusted $R^{2}=0.053, p=0.008$, with specific effects found in $\mathrm{E}(b=-0.185, t=-2.372$, $p=0.018)$ and $C(b=0.191, t=3.327, p=0.001)$ but not in $\mathrm{N}(b=-0.070, t=-1.032, p=0.302)$, $\mathrm{O}(b=0.026, t=0.347, p=0.729)$, and $\mathrm{A}(b=-0.100, t=-1.332, p=0.183)$. 
Table 1. Means, standard deviations and bivariate Pearson's correlation matrix for variables of interest ( $n=201$ with five imputations).

\begin{tabular}{|c|c|c|c|c|c|c|c|c|c|c|c|c|c|}
\hline Variables & Mean & SD + & Skewness $t$ & Kurtosis $t$ & 1 & 2 & 3 & 4 & 5 & 6 & 7 & 8 & 9 \\
\hline Neuroticism & 33.703 & 7.470 & -0.428 & -0.357 & 1 & & & & & & & & \\
\hline Extraversion & 25.185 & 6.434 & -0.340 & 0.047 & $-0.176^{*}$ & 1 & & & & & & & \\
\hline Openness to experience & 28.678 & 6.699 & 0.097 & -0.235 & $0.269 * *$ & $0.187^{* *}$ & 1 & & & & & & \\
\hline Agreeableness & 30.735 & 6.656 & -0.413 & -0.022 & -0.086 & 0.191 ** & $0.175^{*}$ & 1 & & & & & \\
\hline Conscientiousness & 26.967 & 8.990 & -0.185 & -0.306 & $-0.217^{* *}$ & $0.296^{* *}$ & 0.118 & $0.342 * *$ & 1 & & & & \\
\hline Perceived burdensomeness & 23.375 & 10.120 & 0.009 & -0.966 & $0.283^{* *}$ & $-0.179 *$ & -0.083 & -0.081 & -0.088 & 1 & & & \\
\hline Thwarted belongingness & 40.020 & 10.661 & -0.164 & -0.304 & $0.233 * *$ & $-0.292 * *$ & -0.132 & $-0.198^{* *}$ & -0.109 & $0.380 * *$ & 1 & & \\
\hline Acquired capability for suicide & 29.898 & 6.696 & 0.149 & -0.100 & -0.089 & -0.103 & -0.019 & -0.034 & $0.189^{* *}$ & $0.143 *$ & 0.100 & 1 & \\
\hline Suicidal ideation & 14.707 & 8.134 & -0.268 & -0.779 & $0.322 * *$ & $-0.358^{* *}$ & -0.038 & $-0.167^{*}$ & -0.099 & $0.453^{* *}$ & $0.369 * *$ & $0.251 * *$ & 1 \\
\hline
\end{tabular}

Note: * $p$-values significant at the 0.05 threshold; ** $p$-values significant at the 0.01 threshold; $\dagger$ computed with the original data, i.e., $n=200$ (except for suicidal ideation, $n=201$ ). The standard error was 0.172 for skewness and 0.342 for kurtosis. 
We then constructed a fourth model with SI measured by the SSI as the dependent variable and the similar five personality variables as predictors. Additionally, we controlled for two socio-demographic variables susceptible to have a confounding influence, namely gender and age. Suicidal ideation has indeed been identified as more frequent in female than male gender [46,47], and tends to be more prevalent in older than younger age groups $[48,49]$. We transformed gender into a dummy variable, coding 0 for females and 1 for males. The model predicted SI, $F(7,192)=7.877$, Adjusted $R^{2}=0.195$, $p<0.001$, as well as higher $\mathrm{N}(b=0.304, t=3.743, p<0.001)$ and lower $\mathrm{E}(b=-0.416, t=-4.598$, $p<0.001)$. However, no effect was found for $\mathrm{O}(b=-0.062, t=-734, p=0.463)$, A $(b=-0.141$, $t=-1.662, p=0.097)$ and $C(b=0.100, t=1.535, p=0.125)$. Similarly, neither age $(b=-0.017$, $t=-0.423, p=0.672)$ nor gender $(b=-1.232, t=-1.096, p=0.273)$ had a significant influence on SI.

\subsection{Path Analyses}

As detailed in Table 2, path analyses with PB and TB as mediators were poorly adjusted to the data. This was the case for models without $\left(\chi^{2}=65.241, \mathrm{df}=9, p<0.001, \mathrm{CFI}=0.609\right.$, RMSEA $=0.177$ $90 \%$ CI (0.138-0.219) $)$ and with $\left(\chi^{2}=42.551, \mathrm{df}=6, p<0.001, \mathrm{CFI}=0.747, \mathrm{RMSEA}=0.17590 \% \mathrm{CI}\right.$ $(0.127-0.226))$ direct estimates of FFM traits on SI. Although model 2 yielded three degrees of freedom to model 1 , the former was significantly improved $\left(\Delta \chi^{2}=22.69, \Delta \mathrm{df}=3, p<0.001\right)$. All direct effects were significant except A to SI in model 2. Despite $p$-values were unavailable for PB and TB mediation effects of FFM traits on SI, standardized effects ranged from $|0.021|$ to $|0.115|$ suggesting that these effects are weak.

Next we tested a model (model 5) based on significant predictive relationships highlighted in regression analyses. Thus, we included $\mathrm{N}, \mathrm{E}$, and $\mathrm{O}$ in the model and tested the following direct effects: $\mathrm{N}$ to $\mathrm{PB}, \mathrm{N}$ to TB, $\mathrm{N}$ to SI; $\mathrm{E}$ to $\mathrm{TB}, \mathrm{E}$ to SI; $\mathrm{O}$ to $\mathrm{PB}$. As displayed in Table 4, all direct effects were significant but the model did not adjust well to the data $\left(\chi^{2}=60.073, \mathrm{df}=7, p<0.001, \mathrm{CFI}=0.681\right.$, RMSEA $=0.195$ 90\% CI (0.151-0.242)).

Table 2. Estimated unstandardized (with standard errors) and standardized parameters for the regression weights, as well as fit indices, for the two models with PB and TB as mediators in the relationship between FFM variables and SI.

\begin{tabular}{|c|c|c|c|}
\hline \multicolumn{4}{|c|}{ Model 1, fit indices: $\chi^{2}=65.241, \mathrm{df}=9, p<0.001, \mathrm{CFI}=0.609, \mathrm{RMSEA}=0.17790 \% \mathrm{CI}(0.138-0.219)$} \\
\hline Parameter estimates & Unstandardized $\beta$ & Standardized $\beta$ & $p$-value \\
\hline $\mathrm{N}$ to $\mathrm{PB}$ & $0.345(0.091)$ & 0.256 & $<0.001$ \\
\hline$E$ to $P B$ & $-0.221(0.106)$ & -0.141 & 0.038 \\
\hline $\mathrm{E}$ to $\mathrm{TB}$ & $-0.437(0.111)$ & -0.266 & $<0.001$ \\
\hline $\mathrm{A}$ to $\mathrm{TB}$ & $-0.237(0.108)$ & -0.149 & 0.027 \\
\hline PB to SI & $0.294(0.050)$ & 0.375 & $<0.001$ \\
\hline TB to SI & $0.175(0.047)$ & 0.235 & $<0.001$ \\
\hline $\mathrm{N}$ to $\mathrm{SI}$ (indirect) & 0.101 & 0.096 & N/A \\
\hline E to SI (indirect) & -0.141 & -0.115 & N/A \\
\hline A to SI (indirect) & -0.041 & -0.035 & N/A \\
\hline \multicolumn{4}{|c|}{ Model 2, fit indices: $\chi^{2}=42.551, \mathrm{df}=6, p<0.001, \mathrm{CFI}=0.747, \mathrm{RMSEA}=0.17590 \%$ CI $(0.127-0.226)$} \\
\hline Parameter estimates & Unstandardized $\beta$ & Standardized $\beta$ & $p$-value \\
\hline $\mathrm{N}$ to $\mathrm{PB}$ & $0.342(0.092)$ & 0.254 & $<0.001$ \\
\hline$E$ to $P B$ & $-0.215(0.106)$ & -0.137 & 0.043 \\
\hline $\mathrm{E}$ to TB & $-0.437(0.111)$ & -0.266 & $<0.001$ \\
\hline $\mathrm{A}$ to $\mathrm{TB}$ & $-0.238(0.108)$ & -0.150 & 0.027 \\
\hline PB to SI & $0.250(0.049)$ & 0.321 & $<0.001$ \\
\hline TB to SI & $0.104(0.047)$ & 0.140 & 0.027 \\
\hline$N$ to $S I$ & $0.181(0.065)$ & 0.172 & 0.006 \\
\hline E to SI & $-0.278(0.077)$ & -0.229 & $<0.001$ \\
\hline A to SI & $-0.068(0.072)$ & -0.058 & 0.342 \\
\hline $\mathrm{N}$ to $\mathrm{SI}$ (indirect) & 0.085 & 0.081 & N/A \\
\hline E to SI (indirect) & -0.099 & -0.081 & $\mathrm{~N} / \mathrm{A}$ \\
\hline A to SI (indirect) & -0.025 & -0.021 & $\mathrm{~N} / \mathrm{A}$ \\
\hline
\end{tabular}

Note: Standard errors and $p$-values not available for indirect pathway estimates due to missing values. In bold, effects significant at the 0.05 threshold. 
In the same vein, path analysis frameworks using AC as mediator of the effect of FFM traits on SI did not demonstrate adequate fit to the data in both models (model 3: $\chi^{2}=142.311, \mathrm{df}=15, p<0.001$, CFI $=0.111$, RMSEA $=0.20690 \% \mathrm{CI}(0.176-0.238)$; model $4: \chi^{2}=92.562, \mathrm{df}=10, p<0.001, \mathrm{CFI}=0.423$, RMSEA $=0.20390 \%$ CI $(0.166-0.242))$ as described in Table 3. Despite the loss of five degrees of freedom, model 4 had a significantly better adjustment than model 3 as assessed by the Chi-squared analysis $\left(\Delta \chi^{2}=49.749, \Delta \mathrm{df}=5, p<0.001\right)$. In both models, $\mathrm{E}$ (negatively) and $\mathrm{C}$ (positively) had an influence on AC, and AC positively predicted SI. Additionally, direct effects of N (positively) and $\mathrm{E}$ (negatively) on SI were found in model 4. Standardized indirect effects of FFM traits on SI showed low values ranging from $|0.006|$ to $|0.064|$.

Next, we tested a model (model 6) with AC playing a mediating role between FFM variables and SI based on the regression analyses. We included N, E and C, and estimated the following relations: $\mathrm{N}$ to SI; E to AC, E to SI; C to AC. As displayed in Table 4, all direct effects were significant but the model did not adjust well to the data $\left(\chi^{2}=31.452, \mathrm{df}=5, p<0.001, \mathrm{CFI}=0.705, \mathrm{RMSEA}=0.16390 \% \mathrm{CI}\right.$ (0.111-0.219)).

Table 3. Estimated unstandardized (with standard errors) and standardized parameters for the regression weights, as well as fit indices, for the two models with AC as mediator in the relationship between FFM variables and SI.

\begin{tabular}{|c|c|c|c|}
\hline \multicolumn{4}{|c|}{ Model 3, fit indices: $\chi^{2}=142.311, \mathrm{df}=15, p<0.001, \mathrm{CFI}=0.111, \mathrm{RMSEA}=0.20690 \% \mathrm{CI}(0.176-0.238)$} \\
\hline Parameter estimates & Unstandardized $\beta$ & Standardized $\beta$ & $p$-value \\
\hline $\mathrm{N}$ to $\mathrm{AC}$ & $-0.069(0.061)$ & -0.076 & 0.257 \\
\hline $\mathrm{E}$ to $\mathrm{AC}$ & $-0.185(0.071)$ & -0.174 & 0.009 \\
\hline $\mathrm{O}$ to $\mathrm{AC}$ & $0.024(0.068)$ & 0.024 & 0.725 \\
\hline A to $\mathrm{AC}$ & $-0.098(0.069)$ & -0.095 & 0.155 \\
\hline $\mathrm{C}$ to $\mathrm{AC}$ & $0.191(0.051)$ & 0.251 & $<0.001$ \\
\hline $\mathrm{AC}$ to $\mathrm{SI}$ & $0.306(0.082)$ & 0.257 & $<0.001$ \\
\hline $\mathrm{N}$ to SI (indirect) & -0.021 & -0.019 & $\mathrm{~N} / \mathrm{A}$ \\
\hline E to SI (indirect) & -0.057 & -0.045 & $\mathrm{~N} / \mathrm{A}$ \\
\hline $\mathrm{O}$ to SI (indirect) & 0.007 & 0.006 & $\mathrm{~N} / \mathrm{A}$ \\
\hline A to SI (indirect) & -0.030 & -0.024 & $\mathrm{~N} / \mathrm{A}$ \\
\hline C to SI (indirect) & 0.058 & 0.064 & $\mathrm{~N} / \mathrm{A}$ \\
\hline \multicolumn{4}{|c|}{ Model 4, fit indices: $\chi^{2}=92.562, \mathrm{df}=10, p<0.001, \mathrm{CFI}=0.423, \mathrm{RMSEA}=0.20390 \% \mathrm{CI}(0.166-0.242)$} \\
\hline Parameter estimates & Unstandardized $\beta$ & Standardized $\beta$ & $p$-value \\
\hline $\mathrm{N}$ to $\mathrm{AC}$ & $-0.068(0.061)$ & -0.075 & 0.266 \\
\hline $\mathrm{E}$ to $\mathrm{AC}$ & $-0.185(0.071)$ & -0.175 & 0.009 \\
\hline $\mathrm{O}$ to $\mathrm{AC}$ & $0.023(0.068)$ & 0.023 & 0.731 \\
\hline A to $A C$ & $-0.098(0.069)$ & -0.096 & 0.153 \\
\hline $\mathrm{C}$ to $\mathrm{AC}$ & $0.191(0.051)$ & 0.252 & $<0.001$ \\
\hline $\mathrm{AC}$ to $\mathrm{SI}$ & $0.293(0.077)$ & 0.247 & $<0.001$ \\
\hline $\mathrm{N}$ to $\mathrm{SI}$ & $0.349(0.066)$ & 0.322 & $<0.001$ \\
\hline E to SI & $-0.327(0.078)$ & -0.260 & $<0.001$ \\
\hline O to SI & $-0.071(0.074)$ & -0.059 & 0.336 \\
\hline A to SI & $-0.100(0.074)$ & -0.082 & 0.179 \\
\hline C to SI & $0.034(0.057)$ & 0.038 & 0.548 \\
\hline $\mathrm{N}$ to SI (indirect) & -0.020 & -0.018 & $\mathrm{~N} / \mathrm{A}$ \\
\hline E to SI (indirect) & -0.054 & -0.043 & $\mathrm{~N} / \mathrm{A}$ \\
\hline O to SI (indirect) & 0.007 & 0.006 & $\mathrm{~N} / \mathrm{A}$ \\
\hline A to SI (indirect) & -0.029 & -0.024 & $\mathrm{~N} / \mathrm{A}$ \\
\hline C to SI (indirect) & 0.056 & 0.062 & $\mathrm{~N} / \mathrm{A}$ \\
\hline
\end{tabular}

Note: Standard errors and $p$-values not available for indirect pathway estimates due to missing values. In bold, effects significant at the 0.05 threshold. 
Table 4. Estimated unstandardized (with standard errors) and standardized parameters for the regression weights, as well as fit indices, for a model with PB and TB (model 5) and a model with AC (model 6) as mediators in the relationship between FFM variables and SI.

\begin{tabular}{|c|c|c|c|}
\hline \multicolumn{4}{|c|}{ Model 5, fit indices: $\chi^{2}=60.073, \mathrm{df}=7, p<0.001, \mathrm{CFI}=0.681, \mathrm{RMSEA}=0.19590 \% \mathrm{CI}(0.151-0.242)$} \\
\hline Parameter estimates & Unstandardized $\beta$ & Standardized $\beta$ & $p$-value \\
\hline $\mathrm{N}$ to $\mathrm{PB}$ & $0.442(0.091)$ & 0.321 & $<0.001$ \\
\hline $\mathrm{O}$ to $\mathrm{PB}$ & $-0.272(0.101)$ & -0.177 & 0.007 \\
\hline E to TB & $-0.428(0.110)$ & -0.261 & $<0.001$ \\
\hline $\mathrm{N}$ to $\mathrm{TB}$ & $0.268(0.095)$ & 0.189 & 0.005 \\
\hline PB to SI & $0.250(0.048)$ & 0.327 & $<0.001$ \\
\hline TB to SI & $0.110(0.047)$ & 0.148 & 0.020 \\
\hline $\mathrm{N}$ to $\mathrm{SI}$ & $0.181(0.068)$ & 0.172 & 0.008 \\
\hline E to SI & $-0.291(0.068)$ & -0.238 & $<0.001$ \\
\hline $\mathrm{N}$ to SI (indirect) & 0.140 & 0.133 & $\mathrm{~N} / \mathrm{A}$ \\
\hline E to SI (indirect) & -0.047 & -0.039 & $\mathrm{~N} / \mathrm{A}$ \\
\hline O to SI (indirect) & -0.068 & -0.058 & $\mathrm{~N} / \mathrm{A}$ \\
\hline \multicolumn{4}{|c|}{ Model 6, fit indices: $\chi^{2}=31.452, \mathrm{df}=5, p<0.001, \mathrm{CFI}=0.705, \mathrm{RMSEA}=0.16390 \% \mathrm{CI}(0.111-0.219)$} \\
\hline Parameter estimates & Unstandardized $\beta$ & Standardized $\beta$ & $p$-value \\
\hline E to $\mathrm{AC}$ & $-0.181(0.071)$ & -0.172 & 0.011 \\
\hline $\mathrm{C}$ to $\mathrm{AC}$ & $0.180(0.051)$ & 0.238 & $<0.001$ \\
\hline $\mathrm{AC}$ to $\mathrm{SI}$ & $0.302(0.074)$ & 0.253 & $<0.001$ \\
\hline $\mathrm{N}$ to SI & $0.328(0.066)$ & -0.150 & $<0.001$ \\
\hline E to SI & $-0.350(0.078)$ & -0.278 & $<0.001$ \\
\hline E to SI (indirect) & -0.055 & -0.043 & $\mathrm{~N} / \mathrm{A}$ \\
\hline C to SI (indirect) & 0.054 & 0.060 & $\mathrm{~N} / \mathrm{A}$ \\
\hline
\end{tabular}

Note: Standard errors and $p$-values not available for indirect pathway estimates due to missing values. In bold, effects significant at the 0.05 threshold.

\section{Discussion}

This study is the first to investigate the relationship between personality dimensions as defined by the FFM model and the main constructs of the IPTS in a large clinical population with current SI. Our results from correlation and regression analyses are globally in line with the literature and suggest that certain dispositions of personality traits may foster the occurrence of $\mathrm{PB}, \mathrm{TB}$ and $\mathrm{AC}$. When significant findings occurred their effect size remained globally modest, as illustrated by the percentages of variance in $\mathrm{PB}$ and $\mathrm{TB}(9.4 \%$ and $13.5 \%$, respectively) explained by FFM traits through regression equations. However, we did not replicate the findings of Cramer et al. [11,13,14], notably with regard to the trait-interpersonal hypothesis. Overall, this suggests that personality does play a role in the variance of SI or variables approaching SI (that is, in this case, PB and TB from the IPTS) but that the importance of this role should be considered with caution and not yield to over-interpretation. Interestingly, personality was found to be predictive of $\mathrm{AC}$ as well. This is, to our knowledge, the first time that an association between personality and AC is statistically assessed.

In line with the literature and in both correlation and regression analyses, we found a relationship between $\mathrm{N}$ and $\mathrm{PB}$, and between $\mathrm{N}, \mathrm{E}$ and TB. Additionally, $\mathrm{O}$ was a negative predictor of $\mathrm{PB}$, and $\mathrm{E}$ and $\mathrm{A}$ negatively correlated with $\mathrm{PB}$, respectively TB. An association between $\mathrm{N}, \mathrm{E}$, and variables related to suicide desire has already been identified $[9,50]$. Additionally, a conjoint presence of higher levels of $\mathrm{N}$ and lower levels of $\mathrm{E}, \mathrm{A}$ and $\mathrm{C}$ characterized individuals with psychiatric disorders [51] and more specifically SI [19]. Whereas C was associated with neither PB nor TB in our study, the correlation between $\mathrm{A}$ and TB was not surprising as agreeableness is strongly related to interpersonal behavior. Besides, low levels of A might complicate the formation of interpersonal relationships, indirectly fostering feelings of not belonging to a social group [36]. Similarly, the finding that PB was negatively predicted by $\mathrm{O}$ should not be a surprise when one considers that "openness affects social perceptions and the formation of social attitudes, the choice of friends and spouses, political 
activity, and cultural innovation" ([52], p. 257). Thus, our results suggest that the way one considers interpersonal relationships is pivotal in the formation of SI, providing in this way support to the IPTS.

High levels of $C$ and low levels of $E$ were predictive of a greater capability to act on one's suicidal desire, which implies that personality can directly or indirectly contribute to the way one's may acquire the capability to commit suicide as suggested by others $[7,8]$. These studies yet addressed dimensions not considered by the FFM (e.g., psychotism, stoicism, sensation seeking), which limits comparisons with ours. The fact that $\mathrm{E}$ played a role in the acquisition of a construct such as $\mathrm{AC}$, which is comprised of a habituation component, is in line with other studies that found a relationship between $\mathrm{E}$ and habituation. However, in contrast with our results, these studies often concluded that habituation takes place faster in extroverts than introverts $[30,53,54]$. From another standpoint, it has been underscored that medically serious suicide attempters-that is, individuals supposed to have acquired the capability to seriously harm themselves-thought more about suicide preparation and were more precautious against the discovery of their intentions than individuals whose suicide attempts were medically less serious $[55,56]$. This implies that those with medically serious suicide attempt showed features corresponding to high scores on the $\mathrm{C}$ dimension such as achievement striving, self-discipline and deliberation. As participants in our study were included with a mixed criterion of presence of SI and presence of a suicide attempt, as well as different histories of suicide attempts, we were not able to investigate this aspect more specifically. Thus, further research should be conducted, on the one hand, to confirm the role of $\mathrm{E}$ in the development of habituation and other components from which $\mathrm{AC}$ theoretically derives (e.g., opponent processes), and, on the other hand, to specify the interplay of personality and AC in taking different levels of lethality into consideration.

We could not replicate the findings of Cramer and colleagues $[11,13,14]$ in that none of the trait-interpersonal model tested, either with $\mathrm{PB} / \mathrm{TB}$ or with $\mathrm{AC}$, fit the data in an adequate way. This was the case for theory-driven models (i.e., models 1 to 4 ) and models based on regression findings (i.e., models 5 and 6). This is somewhat surprising as direct effects between FFM, IPTS and SI variables were consistently significant; yet the limited sample size and the relative small proportion of variance in IPTS components and SI explained by regression models might imply a lack of statistical power that could account for the poor fit of global models. Similarly, these results might be due to the type of population studied (i.e., patients visiting emergency with suicidal ideation) as it has been proposed that relationships between personality and suicidality could depend on this $[4,11]$. Another possible reason, our measure of outcome was SI while that of Cramer and colleagues was suicide proneness. Yet, suicide proneness has been associated with SI [25], making this assumption unlikely. Finally, contrary to Cramer and collaborators [11,13], we did not allow measurement errors of some of our variables to correlate. While such a procedure may lead to significant improvement of a path analysis model, it appears to be theoretically unjustified in almost all cases [57]. Cramer and colleagues did not provide a detailed rationale for allowing measurement errors to correlate and, as far as we were concerned, we did not have any. It appears then pivotal that trait-interpersonal models continue to be investigated under theory- and evidence-based hypotheses, with various population types and important sample sizes. This constitutes a prerequisite before any definitive conclusions on the viability of this approach can be drawn.

This study had several limitations, which should be taken into account. First, our experimental design did not allow us to collect longitudinal data, which limits the interpretation of the findings in a predictive way. Second, we defined our research hypotheses on the basis of the existing literature. However, studies exploring the relationships between suicide behaviors, the FFM and the IPTS did not consider the same measurement outcomes. Thus, while we used a measurement of SI, others utilized history of SI [9], suicide proneness [11,13,14], and self-injurious behavior [4]. These major differences may have contributed to some of the inconsistent results observed. Third, low internal consistency values in two subscales of the NEO FFI-R, namely $\mathrm{O}$ and $\mathrm{A}$, might imply that items were not sufficient in number to satisfactorily account for these dimensions. This may have impacted our results. In line with that, the use of the 60-item NEO FFI-R rather than the longer, 240-item NEO PI-R did not offer the 
opportunity to analyze the facets of the FFM dimensions. Future studies are encouraged to utilize the NEO PI-R as it proposes a personality profile based on 30 facets, although administration might be difficult to implement in the clinical practice of patients with active suicidal behavior.

\section{Conclusions}

The clinical use of the FFM through specific instruments such as the NEO PI-R or the NEO-FFI-R provides health professionals with information potentially useful in their daily practice. It allows them to identify directions in which the treatment could evolve and to construct strong therapeutic alliances, offering patients and significant others opportunities to become aware of elements remained unconscious, or suggesting patient-specific therapeutic frameworks [58]. However, and despite that clinical research has underscored the relevance of the FFM in psychotherapy [59-61], the reliability of these instruments in the detection of individuals at risk of suicidal events is yet to be supported by additional research.

Bearing in mind that other factors may play a more important part of variance in suicidality than personality, this paper advocates personality as a potential determinant of the desire for suicide and the acquired capability for suicide as conceptualized by the IPTS, a leading theoretical framework in suicidality. Thus, the administration of a personality inventory in the clinical routine should be encouraged, as it could provide health professionals with relevant information regarding the risk of a patient to develop future suicidal ideation or engage in suicidal behavior.

Acknowledgments: We are thankful to François Sarasin, Hélène Richard-Lepouriel, and the medical team of the Geneva University Hospitals emergency department for their precious contributions to this study. This study was funded by the Service of Liaison Psychiatry and Crisis Intervention of the Geneva University Hospitals, Switzerland. It did not benefit from any other grant or funding source.

Author Contributions: Alessandra Canuto, Kerstin Weber, Marc Baertschi and Alessandra Costanza conceived and designed the experiments; Marc Baertschi and Alessandra Costanza performed the experiments; Marc Baertschi and Kerstin Weber analyzed the data; Marc Baertschi and Alessandra Costanza wrote the paper.

Conflicts of Interest: All authors declare that they have no conflict of interest.

\section{References}

1. Joiner, T.E. Why People Die by Suicide; Harvard University Press: Cambridge, MA, USA, 2005.

2. Van Orden, K.A.; Witte, T.K.; Cukrowicz, K.C.; Braithwaite, S.R.; Selby, E.A.; Joiner, T.E. The interpersonal theory of suicide. Psychol. Rev. 2010, 117, 575-600. [CrossRef] [PubMed]

3. Ma, J.; Batterham, P.J.; Calear, A.L.; Han, J. A systematic review of the predictions of the Interpersonal-Psychological Theory of Suicidal Behaviour. Clin. Psychol. Rev. 2016, 46, 34-45. [CrossRef] [PubMed]

4. Ireland, J.L.; York, C. Exploring application of the Interpersonal-Psychological Theory of Suicidal Behaviour to self-injurious behaviour among women prisoners: Proposing a new model of understanding. Int. J. Law Psychiatry 2012, 35, 70-76. [CrossRef] [PubMed]

5. Rogers, M.L.; Joiner, T.E. Borderline Personality Disorder Diagnostic Criteria as Risk Factors for Suicidal Behavior through the Lens of the Interpersonal Theory of Suicide. Arch. Suicide Res. 2016, 1118. [CrossRef] [PubMed]

6. Silva, C.; Ribeiro, J.D.; Joiner, T.E. Mental disorders and thwarted belongingness, perceived burdensomeness, and acquired capability for suicide. Psychiatry Res. 2015, 226, 316-327. [CrossRef] [PubMed]

7. Witte, T.K.; Gordon, K.H.; Smith, P.N.; Van Orden, K.A. Stoicism and sensation seeking: Male vulnerabilities for the acquired capability for suicide. J. Res. Personal. 2012, 46, 384-392. [CrossRef] [PubMed]

8. Christensen, H.; Batterham, P.J.; Mackinnon, A.J.; Donker, T.; Soubelet, A. Predictors of the risk factors for suicide identified by the interpersonal-psychological theory of suicidal behaviour. Psychiatry Res. 2014, 219, 290-297. [CrossRef] [PubMed]

9. DeShong, H.L.; Tucker, R.P.; O'Keefe, V.M.; Mullins-Sweatt, S.N.; Wingate, L.R. Five factor model traits as a predictor of suicide ideation and interpersonal suicide risk in a college sample. Psychiatry Res. 2015, 226, 217-223. [CrossRef] [PubMed] 
10. Harrop, T.M.; Preston, O.C.; Khazem, L.R.; Anestis, M.D.; Junearick, R.; Green, B.A.; Anestis, J.C. Dark traits and suicide: Associations between psychopathy, narcissism, and components of the interpersonal-psychological theory of suicide. J. Abnorm. Psychol. 2017, 126, 928-938. [CrossRef] [PubMed]

11. Cramer, R.J.; Moore, C.E.; Bryson, C.N. A test of the trait-interpersonal model of suicide proneness in emerging adults. Personal. Individ. Differ. 2016, 102, 252-259. [CrossRef]

12. Anestis, J.C.; Finn, J.A.; Gottfried, E.D.; Hames, J.L.; Bodell, L.P.; Hagan, C.R.; Arnau, R.C.; Anestis, M.D.; Arbisi, P.A.; Joiner, T.E. Burdensomeness, Belongingness, and Capability: Assessing the Interpersonal-Psychological Theory of Suicide With MMPI-2-RF Scales. Assessment 2016. [CrossRef] [PubMed]

13. Cramer, R.J.; Garza, M.J.; Henderson, C.E.; Ribeiro, J.D.; Silva, C.; Smith, A.R.; Joiner, T.E.; White, J. A Trait-Interpersonal Perspective on Suicide Risk in Criminal Offenders. Arch. Suicide Res. 2012, 16, 334-347. [CrossRef] [PubMed]

14. Cramer, R.J.; Stroud, C.H.; Fraser, T.; Graham, J. A trait-interpersonal analysis of suicide proneness among lesbian, gay, and bisexual community members. Suicide Life-Threat. Behav. 2014, 44, 601-615. [CrossRef] [PubMed]

15. Digman, J.M. Personality structure: Emergence of the five-factor model. Annu. Rev. Psychol. 1990, 41, 417-440. [CrossRef]

16. Eysenck, H.J. Dimensions of Personality; Praeger: New York, NY, USA, 1947.

17. Costa, P.T.; McCrae, R.R. Influence of extraversion and neuroticism on subjective well-being: Happy and unhappy people. J. Personal. Soc. Psychol. 1980, 38, 668-678. [CrossRef]

18. Chioqueta, A.P.; Stiles, T.C. Personality traits and the development of depression, hopelessness, and suicide ideation. Personal. Individ. Differ. 2005, 38, 1283-1291. [CrossRef]

19. Kerby, D.S. CART analysis with unit-weighted regression to predict suicidal ideation from Big Five traits. Personal. Individ. Differ. 2003, 35, 249-261. [CrossRef]

20. McCrae, R.R.; Costa, P.T. The Five-Factor Theory of personality. In Handbook of Personality: Theory and Research; John, O.P., Robins, R.W., Pervin, L.A., Eds.; Guilford Press: New York, NY, USA, 2008; pp. 159-181.

21. Joiner, T.E.; Van Orden, K.A.; Witte, T.K.; Rudd, M.D. Diagnoses associated with suicide. In The Interpersonal Theory Suicide: Guidance for Working with Suicidal Clients; American Psychological Association: Washington, DC, USA, 2009; pp. 21-51.

22. Martin, M. Neuroticism as predisposition toward depression: A cognitive mechanism. Personal. Individ. Differ. 1985, 6, 353-365. [CrossRef]

23. Swickert, R.J.; Rosentreter, C.J.; Hittner, J.B.; Mushrush, J.E. Extraversion, social support processes, and stress. Personal. Individ. Differ. 2002, 32, 877-891. [CrossRef]

24. Jensen-Campbell, L.A.; Graziano, W.G. Agreeableness as a Moderator of Interpersonal Conflict. J. Personal. 2001, 69, 323-362. [CrossRef]

25. Langhinrichsen-Rohling, J.; Lamis, D.A. Current Suicide Proneness and Past Suicidal Behavior in Adjudicated Adolescents. Suicide Life-Threat. Behav. 2008, 38, 415-426. [CrossRef] [PubMed]

26. Harris, J.D. Habituatory response decrement in the intact organism. Psychol. Bull. 1943, 40, 385-422. [CrossRef]

27. Breimhorst, M.; Hondrich, M.; Rebhorn, C.; May, A.; Birklein, F. Sensory and sympathetic correlates of heat pain sensitization and habituation in men and women. Eur. J. Pain 2012, 16, 1281-1292. [CrossRef] [PubMed]

28. Gurrera, R.J.; O’Donnell, B.F.; Nestor, P.G.; Gainski, J.; McCarley, R.W. The P3 auditory event-related brain potential indexes major personality traits. Biol. Psychiatry 2001, 49, 922-929. [CrossRef]

29. Blanch, A.; Balada, F.; Aluja, A. Habituation in acoustic startle reflex: Individual differences in personality. Int. J. Psychophysiol. 2014, 91, 232-239. [CrossRef] [PubMed]

30. LaRowe, S.D.; Patrick, C.J.; Curtin, J.J.; Kline, J.P. Personality correlates of startle habituation. Biol. Psychol. 2006, 72, 257-264. [CrossRef] [PubMed]

31. Akdag, S.J.; Nestor, P.G.; O’Donnell, B.F.; Niznikiewicz, M.A.; Shenton, M.E.; McCarley, R.W. The startle reflex in schizophrenia: Habituation and personality correlates. Schizophr. Res. 2003, 64, 165-173. [CrossRef]

32. Sheehan, D.V.; Lecrubier, Y.; Sheehan, K.H.; Amorim, P.; Janavs, J.; Weiller, E.; Hergueta, T.; Baker, R.; Dunbar, G.C. The Mini-International Neuropsychiatric Interview (M.I.N.I.): The development and validation of a structured diagnostic psychiatric interview for DSM-IV and ICD-10. J. Clin. Psychiatry 1998, 59 (Suppl. 20), 22-33. [PubMed] 
33. Baertschi, M.; Costanza, A.; Richard-Lepouriel, H.; Pompili, M.; Sarasin, F.; Weber, K.; Canuto, A. The application of the interpersonal-psychological theory of suicide to a sample of Swiss patients attending a psychiatric emergency department for a non-lethal suicidal event. J. Affect. Disord. 2017, 210, 323-331. [CrossRef] [PubMed]

34. Aluja, A.; García, O.; Rossier, J.; García, L.F. Comparison of the NEO-FFI, the NEO-FFI-R and an alternative short version of the NEO-PI-R (NEO-60) in Swiss and Spanish samples. Personal. Individ. Differ. 2005, 38, 591-604. [CrossRef]

35. McCrae, R.R.; Costa, P.T. A contemplated revision of the NEO Five-Factor Inventory. Personal. Individ. Differ. 2004, 36, 587-596. [CrossRef]

36. Costa, P.T.; McCrae, R.R. Revised NEO Personality Inventory (NEO PI-R) and NEO Five-Factor-Inventory (NEO-FFI) Professional Manual; Psychological Assessment Resources: Odessa, FL, USA, 1992.

37. Van Orden, K.A.; Cukrowicz, K.C.; Witte, T.K.; Joiner, T.E. Thwarted belongingness and perceived burdensomeness: Construct validity and psychometric properties of the Interpersonal Needs Questionnaire. Psychol. Assess. 2012, 24, 197-215. [CrossRef] [PubMed]

38. Wachtel, S.; Vocks, S.; Edel, M.A.; Nyhuis, P.; Willutzki, U.; Teismann, T. Validation and psychometric properties of the German Capability for Suicide Questionnaire. Compr. Psychiatry 2014, 55, 1292-1302. [CrossRef] [PubMed]

39. Beck, A.T.; Kovacs, M.; Weissman, A. Assessment of suicidal intention: The Scale for Suicide Ideation. J. Consult. Clin. Psychol. 1979, 47, 343-352. [CrossRef] [PubMed]

40. De Man, A.F.; Balkou, S.; Iglesias, R. Une version canadienne française du sondage sur les expériences vécues. Santé mentale au Québec 1987, 12, 181-183. [CrossRef]

41. De Man, A.F.; Leduc, C.P.; Labrèche-Gauthier, L. A French-Canadian scale for suicide ideation for use with adolescents. Can. J. Behav. Sci./Rev. Can. Sci. Comport. 1993, 25, 126-134. [CrossRef]

42. World Health Organization Process of Translation and Adaptation of Instruments. Available online: http:/ / www.who.int/substance_abuse/research_tools/translation/en/ (accessed on 29 March 2018).

43. White, I.R.; Royston, P.; Wood, A.M. Multiple imputation using chained equations: Issues and guidance for practice. Stat. Med. 2011, 30, 377-399. [CrossRef] [PubMed]

44. Kim, H.-Y. Statistical notes for clinical researchers: assessing normal distribution (2) using skewness and kurtosis. Restor. Dent. Endod. 2013, 38, 52-54. [CrossRef] [PubMed]

45. Cohen, J. Statistical Power Analysis for the Behavioral Sciences, 2nd ed.; Lawrence Erlbaum Associates: Hillsdale, NJ, USA, 1988; ISBN 0805802835.

46. Kim, S.M.; Han, D.H.; Trksak, G.H.; Lee, Y.S. Gender differences in adolescent coping behaviors and suicidal ideation: Findings from a sample of 73,238 adolescents. Anxiety Stress Coping 2014, 27, 439-454. [CrossRef] [PubMed]

47. Yu, S.S.V.; Sung, H.E. Suicidal ideation of probationers: Gender differences. Crisis 2015, 36, 424-432. [CrossRef] [PubMed]

48. Jo, A.; Jeon, M.; Oh, H. Age-differentiated Risk Factors of Suicidal Ideation among Young and Middle-aged Korean Adults. Osong Public Health Res. Perspect. 2017, 8, 201-210. [CrossRef] [PubMed]

49. Park, E.; Lee, H.Y. Factors Influencing Suicidal Ideation Among Korean Adults by Age: Results of the 2010-2011 Korean Health and Nutrition Examination Survey. Community Ment. Health J. 2015, 987-993. [CrossRef] [PubMed]

50. Su, M.-H.; Chen, H.-C.; Lu, M.-L.; Feng, J.; Chen, I.-M.; Wu, C.-S.; Chang, S.-W.; Kuo, P.-H. Risk profiles of personality traits for suicidality among mood disorder patients and community controls. Acta Psychiatr. Scand. 2018, 137, 30-38. [CrossRef] [PubMed]

51. Malouff, J.M.; Thorsteinsson, E.B.; Schutte, N.S. The relationship between the five-factor model of personality and symptoms of clinical disorders: A meta-analysis. J. Psychopathol. Behav. Assess. 2005, 27, 101-114. [CrossRef]

52. McCrae, R.R.; Sutin, A.R. Openness to experience. In Handbook of Individual Differences in Social Behavior; Leary, M.R., Hoyle, R.H., Eds.; Guilford: New York, NY, USA, 2003; Volume 6, pp. 257-273.

53. Eysenck, H.J. Personality: Biological foundations. In The Neuropsychology of Individual Differences; Vernon, P.A., Ed.; Academic Press: San Diego, CA, USA, 1994; pp. 151-207, ISBN 9780127186702.

54. Salters-Pedneault, K.; Ruef, A.M.; Orr, S.P. Personality and psychophysiological profiles of police officer and firefighter recruits. Personal. Individ. Differ. 2010, 49, 210-215. [CrossRef] 
55. Levi, Y.; Horesh, N.; Fischel, T.; Treves, I.; Or, E.; Apter, A. Mental pain and its communication in medically serious suicide attempts: An "impossible situation." J. Affect. Disord. 2008, 111, 244-250. [CrossRef] [PubMed]

56. Horesh, N.; Levi, Y.; Apter, A. Medically serious versus non-serious suicide attempts: Relationships of lethality and intent to clinical and interpersonal characteristics. J. Affect. Disord. 2012, 136, 286-293. [CrossRef] [PubMed]

57. Hermida, R. The problem of allowing correlated errors in structural equation modeling: Concerns and considerations. Comput. Methods Soc. Sci. 2015, 3, 5-17.

58. Costa, P.T.; Rolland, J.-P.; De Fruyt, F.; De Clercq, B.; McCrae, R.R. Le modèle à cinq facteurs et l'utilisation du NEO PI-R en pratique psychiatrique. In Psychiatrie de L'adulte et de L'adolescent; Guelfi, J.D., Rouillon, F., Eds.; Masson: Paris, France, 2012; pp. 129-135.

59. Miller, T.R. The Psychotherapeutic Utility of the Five-Factor Model of Personality: A Clinician's Experience. J. Personal. Assess. 1991, 57, 415-433. [CrossRef] [PubMed]

60. Mutén, E. Self-reports, spouse ratings, and psychophysiological assessment in a behavioral medicine program: An application of the five-factor model. J. Personal. Assess. 1991, 57, 449-464. [CrossRef] [PubMed]

61. MacKenzie, K.R. Using personality measurements in clinical practice. In Personality Disorders and the Five-Factor Model of Personality; Costa, P.T., Jr., Widiger, T.A., Eds.; American Psychological Association: Washington, DC, USA, 2002; pp. 377-390.

(C) 2018 by the authors. Licensee MDPI, Basel, Switzerland. This article is an open access article distributed under the terms and conditions of the Creative Commons Attribution (CC BY) license (http://creativecommons.org/licenses/by/4.0/). 